\title{
To Treat or Not to Treat: The Impact of Hairstyle on Implicit and Explicit Perceptions of African American Women's Competence
}

\author{
Boluwatife H. Aladesuru*, Debby Cheng*, Dana Harris*, Arielle Mindel*, Madalina Vlasceanu \\ Department of Psychology, Princeton University, Princeton, USA \\ Email:mov@princeton.edu
}

How to cite this paper: Aladesuru, B.H., Cheng, D., Harris, D., Mindel, A., \& Vlasceanu, M. (2020). To Treat or Not to Treat: The Impact of Hairstyle on Implicit and Explicit Perceptions of African American Women's Competence. Open Journal of Social Sciences, 8, 13-22. https://doi.org/10.4236/jss.2020.810002

Received: September 6, 2020

Accepted: September 27, 2020

Published: September 30, 2020

Copyright $\odot 2020$ by author(s) and Scientific Research Publishing Inc. This work is licensed under the Creative Commons Attribution International License (CC BY 4.0).

http://creativecommons.org/licenses/by/4.0/

\section{(c) (i) Open Access}

\begin{abstract}
African American women wearing their natural Afrocentric hair without altering its texture have long been discriminated against in the workplace, at school, in the military, in the justice system, and more. This phenomenon has been found to be mainly driven by the notion that African American women wearing their natural hair are less professional than African American women wearing chemically treated, Eurocentric hair. In prior work, dimensions such as perceived dominance, intelligence, and unpleasantness have been explored as potential mechanisms playing a role in the relationship between African American hair and perceived professionalism. Here, we explore an additional such dimension: perceived competence. In a sample of 186 predominantly Caucasian Cloud Research participants, we found that African American women wearing their natural Afrocentric hair were perceived both implicitly and explicitly as being less competent than African American women wearing Eurocentric hair, and that the implicit and explicit attitudes were not correlated. These findings are relevant to understanding barriers that may hinder African American women in their academic and professional careers.
\end{abstract}

\section{Keywords}

Afrocentric Hair, Perceived Competence, Bias, Discrimination

\section{Introduction}

In 2018, an 11-year-old girl was sent home from her Louisiana private school for breaking the school's dress code (Rosenblatt, 2018). The offense? She was wearing braids, a form of hair extensions, commonly used by African American *Equal contribution; author names in alphabetical order. 
women and girls. The policy against extensions of all kinds, which would largely affect African American female students, had been implemented just the summer before (Rosenblatt, 2018). In other cases, African American children have been kept out of school on the grounds that administrators considered their hairstyles a distraction to other students (Rosenblatt, 2018). And these restrictions reach far beyond the classroom. Several other institutions in the United States have demonstrated a history of policing African Americans' hair and penalizing them for wearing hairstyles that maintain their natural texture. For instance, the United States Armed Forces banned women from wearing their hair in twists and dreadlocks, calling the styles "exaggerated", and fired African American employees for wearing their hair in cornrows and dreadlocks (Byrd \& Tharps, 2014). In the political sphere, African American women candidates wearing natural hair elicited more negative attitudes than their other female competitors (Lemi \& Brown, 2019). And in the workplace, African American women wearing Eurocentric hairstyles were rated more positively than women wearing Afrocentric hairstyles (Adegbembo, 2019). Therefore, African American women wearing their natural hair, considered outside the Eurocentric standard, risk social isolation and limited employment opportunities (Robinson-Moore, 2008).

Research in psychology and sociology provides some context and several potential mechanisms for this pattern of discriminatory behavior against African American women on the basis of hair. In 2015, Opie and Phillips studied perceptions of professionalism in African American women wearing Afrocentric hairstyles compared to Eurocentric hairstyles. The researchers found that African American women with Afrocentric hairstyles were rated as less professional than women with Eurocentric hairstyles by a sample of participants of varying racial and ethnic backgrounds. In follow-up studies, the authors compared this effect in African American and Caucasian participants and showed that while participants of both races displayed the effect, the effect was stronger in African American participants. Similarly, it was only among African American participants that the perceived dominance of African American women with Afrocentric hairstyles was found to mediate the relationship between hair texture and professionalism ratings. Opie and Phillips explained that this mediating effect may be the result of an association between Afrocentric hair and race-related protest or militancy within the African American community (Opie \& Phillips, 2015). They also theorized more broadly that if this effect was to exist in Caucasian perceivers, it could occur as a penalty for the dominance perceived by outgroup members when African American women choose to wear a hairstyle that expresses their distinctiveness from traditional Eurocentric hairstyles and thus violate the norm of belongingness in the workplace. This perceived dominance may additionally cause women to be seen as less professional, as dominance is typically regarded as a masculine trait, and women who display it may be further penalized (Opie \& Phillips, 2015). 
Besides explicit biases, it is also imperative to understand the role of implicit biases in this equation as these cognitions can operate unconsciously and affect individuals' understanding, actions, and decisions outside of an individual's awareness (Greenwald \& Krieger, 2006). Importantly, implicit attitudes are not always correlated with a person's explicit beliefs and values (Bargh, 1999; Rooth, 2008). The literature suggests that another mechanism why women wearing natural African American hairstyles are seen as less professional could be an intelligence-based explanation (Rosette \& Dumas, 2007). This model posits that African Americans are implicitly associated with lower levels of intelligence (which they showed evidence for with an implicit association test), and Afrocentric hairstyles activate this stereotype to a higher degree than Eurocentric hairstyles, which leads to perceptions of lower perceptions of professionalism for African American women wearing afro-textured hairstyles compared to African American women wearing Eurocentric hairstyles (Rosette \& Dumas, 2007).

In addition to the dimensions of dominance and intelligence, a third relevant variable examined in relation to African American hair and professionalism is unpleasantness (Johnson et al., 2017). Johnson and colleagues found that while again, participants explicitly rated African American women with Afrocentric hairstyles as less professional than African American women with Eurocentric hairstyles, they also implicitly perceived African American women with Afrocentric hair to be more unpleasant, as measured by an implicit association test. Importantly, the authors found that whether or not participants' implicit and explicit biases were correlated depended on their race - whereas most Caucasian participants showed both explicit and implicit biases against textured hair, African American participants showed an implicit bias but positive explicit attitudes towards textured hair (Johnson et al., 2017).

In the present research, we explore an additional dimension relevant in the effect of African Americans' hairstyle on their perceived professionalism: perceived competence. Competence is a construct distinct from intelligence as it incorporates characteristics beyond cognitive and academic prowess, integrating efficient and strong performance in a variety of areas such as social interactions, self-regulation (e.g. self-control, task management), self-motivation, introspection, and interaction with one's environment (Le Deist \& Winterton, 2005). For its broader inclusion of traits valued in workers, competence has been considered a more useful dependent variable in workplace related studies (Le Deist \& Winterton). Thus, we conjectured competence is a dimension of critical relevance in explaining attitudes towards women in the workplace. Additionally, from a theoretical standpoint, competence is one of the two main components of the stereotype content model (Fiske, Cuddy, Glick, \& Xu, 2002) one of the most supported models of impression formation. This model posits that all interpersonal impressions form along two main dimensions: warmth and competence. While warmth refers to trustworthiness, competence refers to agency, and both these dimensions are fundamental in predicting others' behaviors (Fiske et al., 2002). Thus, competence is likely to play a key role in the current matter as well. 
In the current experiment, after signing the consent form, participants first completed an implicit association test (IAT; Greenwald et al., 1998) a widely used tool in assessing implicit bias by measuring associations between concepts. In our adaptation of the IAT, the concepts were natural/Afrocentric (e.g., braids, afro) versus Eurocentric (e.g., permed, waved) African American hairstyles and competence (e.g., capable vs. amateur). In the second part of the experiment (i.e., the explicit association test), participants were exposed to a series of images of African American women wearing different hairstyles and were asked to rate how competent each woman appeared on a Likert scale ranging from "very incompetent" to "very competent". Lastly, participants were asked to complete a demographic questionnaire, after which they were debriefed.

We hypothesized detecting an implicit bias in the form of women wearing their natural Afrocentric hair being implicitly associated with lower competence compared to the same women wearing Eurocentric hairstyles (H1). We also hypothesized an explicit bias, expecting African American women wearing natural Afrocentric hairstyles to be explicitly rated as less competent than African American women wearing Eurocentric hairstyles (H2). Finally, we hypothesized a positive linear relationship between these implicit and explicit attitudes (H3).

\section{Methods}

\subsection{Open Science Practices}

We preregistered the study's experimental design and hypotheses on an open science platform: https://aspredicted.org/blind.php? $x=w j 4 d f 7$. In addition, the pilot study results, and the data can be found on the study's open science framework page:

https://osf.io/fhtae/?view only=528b548401384b95bc2cdd960a250d13.

\subsection{Participants}

To detect an effect size of 0.2 for a within-subject comparison with 0.80 statistical power we estimated a sample of 200 participants. Participants were recruited on Cloud Research (Litman, Robinson, \& Abberbock, 2016), an Internet-based research platform similar to Amazon Mechanical Turk (MTurk) and were compensated at the platform's standard rate. In total we recruited 206 participants, of which 20 were excluded from the analysis based on preregistered criteria (i.e., attention checks), leaving a final dataset of 186 participants (Mage $=46.4$, SDage $=17.3 ; 61.8 \%$ women; $72 \%$ Caucasian, $10 \%$ African American, $8 \%$ Asian, $7 \%$ Hispanic, $2 \%$ Other). The study protocol was approved by the Princeton University Institutional Review Board.

\subsection{Stimulus Materials}

We constructed a set of four words depicting natural African American hairstyles (i.e., "afro", "braids", "cornrows", "dreadlocks) and a set of four words depicting Eurocentric African American hairstyles (i.e., "straightened", "waved", 
"crimped", "permed") to be used in constructing the IAT. We also constructed a set of 4 words depicting high competence (i.e., "capable", "skilled", "equipped", "accomplished") and 4 words depicting low competence (i.e., , "inadequate", "amateur", "inept", "inefficient") also for the IAT.

For the explicit competence ratings, we used the set of 6 headshots of an African American woman wearing different hairstyles from Johnson and colleagues (2017). In each image, the woman had her face pixelated to control for facial expressions. Three of the styles were natural (i.e., afro, braids, and dreadlocks) and three were chemically altered to appear as more Eurocentric (i.e., long-straight, long-wavy, and short-wavy).

\subsection{Design and Procedure}

Participants were told they would participate in an experiment about people's opinions and were directed to the survey on the Qualtrics platform. After signing the informed consent form, participants were exposed to information explaining the differences between chemically treated (Eurocentric) hairstyles and natural or untreated (Afrocentric) hairstyles. Treated hairstyles were described as "African American hairstyles in which the original texture has been altered via chemical or heat treatments" and untreated styles were described as "African American hairstyles in which the original texture is maintained". Then, participants completed the Implicit Association Test (created using IATGen). This test had 4 phases. In the first phase, participants were shown a randomized succession of words describing either natural/untreated or Eurocentric/treated hairstyles. These words appeared one at a time on the center on the screen. On the same screen, in the upper corners of the screen were the two category names (treated and untreated). Participants were instructed to press specific keys on the left or right side of their keyboards to denote whether the word on the center of the screen belonged to the left or right category in the upper corners of the screen. If participants pressed the key corresponding to the wrong category, a red " $X$ " appeared on screen, and they were not allowed to continue until the correct answer was given. The first phase consisted of 20 such trials. Similarly, in the second phase, participants were shown a randomized succession of words describing either high or low competence attributes, and these two category names (competent and incompetent) were again displayed on the upper corners of the screen. Participants were instructed to perform the same categorization task for 20 trials. The last two phases contained the critical trials (40 trials). In the third phase, the words appearing in the center of the screen were mixed between the hairstyle words and the competence words. In the upper corners, the categories were now paired (e.g., treated and competent on the left and untreated and incompetent on the right) and participants did the same categorization task. In the last phase, the opposite pairing of the categories was displayed (e.g., treated and incompetent on the left and untreated and competent on the right). The order of the pairings in phases 3 and 4 , and the left/right category as- 
signments were randomized across participants. Based on our first hypothesis, we will refer to the treated-competent/untreated-incompetent as the congruent trials and the untreated-competent/treated-incompetent as the incongruent trials. The test measures reaction times to each trial, with the logic being that faster reaction times on critical trials reveal stronger associations between the paired categories than slower reaction times. These associations have been interpreted to denote implicit attitudes or biases.

After completing the IAT, participants were shown a series of headshots and were instructed to rate each person on how competent they appeared on a 5-point Likert scale from "Very incompetent" to "Very competent". The images were of the same African American woman, with a blurred, pixelated face to mask any facial expressions, wearing either natural (untreated) or Eurocentric (treated) hairstyles. After rating each image, participants were asked to complete a demographic questionnaire, after which they were debriefed and compensated for their participation.

\subsection{Analysis and Coding}

Implicit attitudes were operationalized by a mean $\mathrm{D}$-score, a directional measure of preference (Carpenter et al., 2018). More specifically, a D-score is the effect size of each participant's implicit attitude regarding hairstyle and competence. This was computed by subtracting the participant's reaction times in the incongruent critical trials from their reaction times in the congruent critical trials and dividing this difference by the pooled standard deviation (Carpenter et al., 2018). Thus, the magnitude of an individual's D-score reflects the direction and strength of a participant's implicit association, such that the higher the D-score, the stronger the association of treated hair with competence and untreated hair with incompetence and vice-versa.

\section{Results}

\subsection{Implicit Associations}

To investigate our first hypothesis, that African American women wearing their natural hair are implicitly associated with lower competence levels compared to African American women wearing Eurocentric hairstyles, we conducted a one sample t-test comparing participants' D-scores to zero (the null hypothesis of no implicit association between the dimensions of hairstyle and competence). We found that, as hypothesized, participants' D-scores were significantly higher than zero $(\mathrm{M}=0.221, \mathrm{SD}=0.614), \mathrm{t}(185)=4.918, p<0.001, \mathrm{~d}=0.36$, CI $[0.13,0.31]$. This indicates that participants' reaction times in the congruent condition were significantly faster than in the incongruent condition (Figure 1(a)). This result suggests that participants have a strong implicit association between treated hair and competence and untreated hair and incompetence. This effect was not different for female $(\mathrm{M}=0.20, \mathrm{SD}=0.64)$ and male $(\mathrm{M}=0.25, \mathrm{SD}=0.57)$ participants $(p=0.59)$, suggesting the generalizability of this implicit bias across 


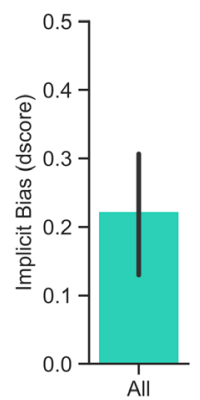

(a)

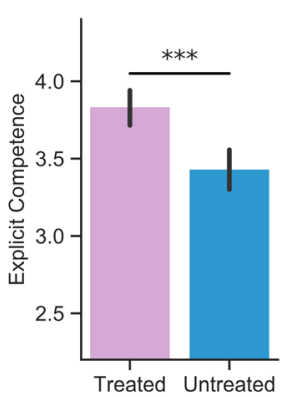

(b)

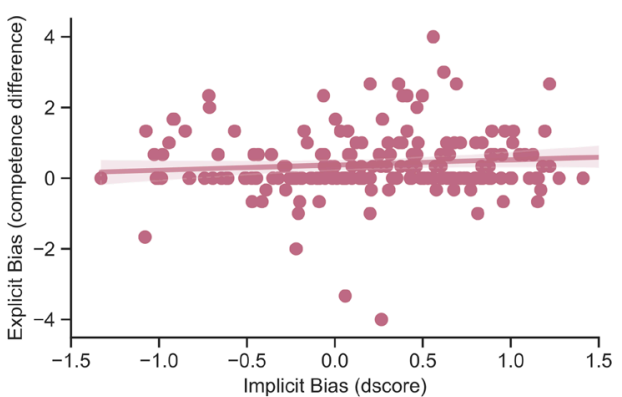

(c)

Figure 1. (a) The implicit bias against women wearing natural (untreated) hair, captured byparticipants' D-scores, a standardized measure of the IAT; (b) Explicit perceived competence of women wearing treated (in pink) and untreated (in blue) hairstyles. Error bars represent \pm 1 standard error of the mean. The triple star annotation indicates a p-value smaller than 0.001; (c) Explicit bias (explicit competence of treated trials minus explicit competence of untreated trials) as a function of Implicit bias (D-scores).

genders. Given the racial distribution of our sample (i.e., mostly Caucasian participants) we were not able to compare the degree of this effect across participants' races.

\subsection{Explicit Associations}

To investigate our second hypothesis, that African American women wearing natural hairstyles are explicitly rated as less competent than African American women wearing Eurocentric hairstyles, we conducted a paired t-test. We found that African American women wearing natural hairstyles were indeed rated as less competent $(\mathrm{M}=3.42, \mathrm{SD}=0.92)$ than African American women wearing Eurocentric hairstyles $(\mathrm{M}=3.83, \mathrm{SD}=0.78), \mathrm{t}(185)=5.88, p<0.001, \mathrm{~d}=0.47$, CI $[0.26,0.54]$, confirming our second hypothesis (Figure $1(\mathrm{~b})$ ). This explicit difference was also not different for female $(\mathrm{M}=0.34, \mathrm{SD}=0.89)$ and male $(\mathrm{M}=$ $0.50, \mathrm{SD}=1.00)$ participants $(p=0.25)$, suggesting the generalizability of the explicit bias across genders.

\subsection{The Relationship between Implicit and Explicit Associations}

To investigate our last hypothesis, of a positive linear relationship between the implicit and explicit associations of hairstyle and competence, we ran a Pearson correlation between participants' implicit attitudes (D-scores) and their explicit attitudes (competence ratings). Contrary to our expectation, we did not find a significant correlation between the two variables (Pearson's $\mathrm{r}=0.096, \mathrm{t}(184)=$ $1.31, p=0.19$, CI $[-0.04,0.23]$ (Figure $1(\mathrm{c})$ ). We again did not find any gender differences, as this correlation was not significant for our female (Pearson's $\mathrm{r}=$ $0.10, p=0.26$ ) or male participants (Pearson's $\mathrm{r}=0.07, p=0.55$ ).

\section{Discussion}

We found that African American women wearing Eurocentric hairstyles were seen as more competent, both implicitly and explicitly, than African American 
women wearing natural Afrocentric hairstyles, revealing an explicit and implicit bias against African American women wearing natural hairstyles. However, the implicit and explicit associations of competence and hairstyles were not significantly correlated, suggesting perhaps a lack of awareness of the implicit bias (Devine, 1989; Wilson, Lindsey, \& Schooler, 2000).

Our findings complement and extend prior work in meaningful ways. First, the result that African American women wearing natural hairstyles were explicitly rated as less competent aligns with Opie and Phillips's (2015) result that African American women wearing afro-textured hairstyles were explicitly rated as less professional. Although the authors offer a dominance-related explanation for their result, the competence dimension we investigated here could offer an additional mechanism that might explain their unveiled effect. Second, our finding revealing an implicit association between African American women wearing natural hairstyles and less competence fits with and complements prior work showing a similar implicit association with less intelligence (Rosette \& Dumas, 2007) and with unpleasantness (Johnson et al., 2017). Our results extend the literature by introducing the dimension of competence to the investigation of the outcomes of African American women's hairstyle choices. Competence incorporates characteristics beyond cognitive and academic prowess, integrating efficient and strong performance in a variety of areas such as social interactions, self-regulation (e.g. self-control, task management), self-motivation, introspection, and interaction with one's environment (Le Deist \& Winterton, 2005). For its broader inclusion of traits valued in workers, competence has been considered a more useful dependent variable in workplace related studies (Le Deist \& Winterton). This dimension of critical importance also gives its theoretical importance as one of the two core components of the main impression formation model (Fiske et al., 2002). Here, we show how African American women's hairstyle is perceived on the competence dimension of the model. This literature would benefit from future work investigating the warmth dimension in this context. The current study also extends the literature by analyzing both implicit and explicit hairstyle biases within the same sample, revealing the lack of a linear relationship between the two constructs.

Overall, these findings have significant implications for understanding the challenges African American women who decide to wear natural hairstyles may face in professional settings. Not only do they face the risk of being discriminated against due to explicit perceptions of natural hairstyles as conveying less competence than Eurocentric hairstyles (Koval \& Rosette, 2020), they may also face the potential discriminatory repercussions of implicit biases related to evaluations of competence. Recent studies have suggested that implicit and explicit biases related to evaluations of professional attributes may contribute to workplace discrimination in distinct ways (Rooth, 2007; Rooth, 2008). Whereas explicit biases are associated with situations in which individuals have sufficient time to deliberate their actions, implicit biases are believed to be activated in situations in which individuals are paying little attention to the task or are under 
time pressure to make a decision (Rooth, 2007). Thus, an employer who consciously discriminates against a certain applicant group due to a variety of explicit attitudes, may additionally unconsciously discriminate against that group given the influence of implicit biases during the hiring process (Rooth, 2007). Even for self-professed "equal opportunity employers", who might not be aware of or believe that they hold negative attitudes toward natural hairstyles, implicit biases may manifest as inadvertent differential treatment in terms of hiring rates and the job opportunities offered (Rooth, 2007). Thus, the decisions African American women make about their hair are not inconsequential and can have a long-term impact on what opportunities they are afforded and on their ability to advance professionally. Altogether, our findings suggest that two distinct forces work against African American women who choose to wear their hair naturally in professional settings.

Future research should investigate the specific impact of such biases on professional behaviors, such as employers' hiring or promoting decisions. Importantly, our study suggests the need to raise awareness about this particular implicit bias, as it can operate unconsciously and may lead to unintended discrimination by employers. Devine and colleagues (2012) have shown that it is possible to reduce implicit biases by promoting and increasing awareness about them. Thus, our society would highly benefit from future work investigating potential interventions aimed at raising awareness and revealing strategies employers could use to reduce implicit biases against African American women's natural hairstyles as well as to promote more equitable treatment of all employees and applicants.

\section{Acknowledgements}

We thank the Department of Psychology at Princeton University for funding this project, Prof. Nicole Shelton for meaningful comments on the manuscript, and reviewers for crucial suggestions.

\section{Conflicts of Interest}

The authors declare no conflicts of interest.

\section{References}

Adegbembo, B. F. (2019). CEOs Don't Wear Afros: Exploring the Justification-Suppression of Prejudice against Black Women in the Workplace. London: The University of Western Ontario.

Bargh, J. A. (1999). The Cognitive Monster: The Case against the Controllability of Automatic Stereotype Effects. In Dual-Process Theories in Social Psychology (pp. 361-382). New York: Guilford Press.

Byrd, A., \& Tharps, L. (2014). Hair Story: Untangling the Roots of Black Hair in America. New York: Macmillan.

Carpenter, T., Pogacar, R., Pullig, C., Kouril, M., Aguilar, S., LaBouff, J. P., Isenberg, N., \& Chakroff, A. (2018). Survey-Software Implicit Association Tests: A Methodological 
and Empirical Analysis. https://doi.org/10.31234/osf.io/hgy3z

Devine, P. G., Forscher, P. S., Austin, A. J., \& Cox, W. T. L. (2012). Long-Term Reduction in Implicit Race Bias: A Prejudice Habit-Breaking Intervention. Journal of Experimental Social Psychology, 48, 1267-1278. https://doi.org/10.1016/j.jesp.2012.06.003

Fiske, S. T., Cuddy, A. J. C., Glick, P., \& Xu, J. (2002). A Model of (Often Mixed) Stereotype Content: Competence and Warmth Respectively Follow from Perceived Status and Competition. Journal of Personality and Social Psychology, 82, 878-902. https://doi.org/10.1037/0022-3514.82.6.878

Greenwald, A. G., \& Krieger, L. H. (2006). Implicit Bias: Scientific Foundations. California Law Review, 94, 945-967. https://doi.org/10.2307/20439056

Greenwald, A. G., McGhee, D. E., \& Schwartz, J. L. K. (1998). Measuring Individual Differences in Implicit Cognition: The Implicit Association Test. Journal of Personality and Social Psychology, 74, 1464-1480. https://doi.org/10.1037/0022-3514.74.6.1464

Johnson, A. M., Godsil, R. D., MacFarlane, J., Aronson, J., Balcetis, E., Barreto, M., Bester, D., Blain, L., Charles, C., Dasgupta, N., Glaser, J., Goff, P. A., Harber, K., Hockett, D., Kang, J., \&Okonofua, J. (2017). The “Good Hair" Study: Explicit and Implicit Attitudes toward Black Women's Hair (p. 18). Newark, NJ: Perception Institute.

Koval, C. Z., \& Rosette, A. S. (2020). The Natural Hair Bias in Job Recruitment. Social Psychological and Personality Science. https://doi.org/10.1177/1948550620937937

Le Deist, F. D., \& Winterton, J. (2005). What Is Competence? Human Resource Development International, 8, 27-46. https://doi.org/10.1080/1367886042000338227

Lemi, D. C., \& Brown, N. E. (2019). Melanin and Curls: Evaluation of Black Women Candidates. The Journal of Race, Ethnicity, and Politics, 4, 259-296.

https://doi.org/10.1017/rep.2019.18

Litman, L., Robinson, J., \& Abberbock, T. (2016). TurkPrime.Com: A Versatile Crowdsourcing Data Acquisition Platform for the Behavioral Sciences. Behavior Research Methods, 49, 433-442. https://doi.org/10.3758/s13428-016-0727-Z

Opie, T. R., \& Phillips, K. W. (2015). Hair Penalties: The Negative Influence of Afrocentric Hair on Ratings of Black Women's Dominance and Professionalism. Frontiers in Psychology, 6, Article No. 1311. https://doi.org/10.3389/fpsyg.2015.01311

Robinson-Moore, C. L. (2008). Beauty Standards Reflect Eurocentric Paradigms-So What? Skin Color, Identity, and Black Female Beauty. The Journal of Race \& Policy, 4, 66-85.

https://search.proquest.com/docview/212407324/citation/CFE2D3A1C4D64678PQ/1

Rooth, D.-O. (2007). Implicit Discrimination in Hiring: Real World Evidence. IZA Discussion Papers No. 2764, Bonn: Institute for the Study of Labor (IZA). http://nbn-resolving.de/urn:nbn:de:101:1-20080402107

Rooth, D.-O. (2008). Automatically Activated Stereotypes and Differential Treatment against the Obese in Hiring. IZA Discussion Papers, Bonn: Institute for the Study of Labor (IZA).

Rosenblatt, K. (2018). Louisiana Girl Sent Home from School over Braided Hair Extensions. NBC News.

https://www.nbcnews.com/news/nbcblk/louisiana-girl-sent-home-school-over-braided -hair-extensions-n902811

Rosette, A. S., \& Dumas, T. L. (2007). The Hair Dilemma: Conform to Mainstream Expectations or Emphasize Racial Identity. Duke Journal of Gender Law \& Policy, 14, 407-422. 